Check for updates

Cite this: RSC Adv., 2018, 8, 26237

\title{
Synthesis of Zn-based metal-organic frameworks in ionic liquid microemulsions at room temperature $\dagger$
}

\author{
Ranfeng Ye, (D) Min Ni, Yuanyuan Xu, Hao Chen (D) and Shengqing Li (D) *
}

For the first time, $\mathrm{Zn}$-metal-organic frameworks ( $\mathrm{Zn}$-MOFs) were prepared using $\mathrm{Zn}^{2+}$ and the aromatic ligand 1,3,5-benzenetricarboxylic acid (BTC) in ionic liquid microemulsions stabilized by the surfactant TX-100. This proposed environmentally friendly approach to synthesize $\mathrm{Zn}-\mathrm{MOFs}$ is simple, requires no energy input, and operates at room temperature. The synthesized Zn-MOFs were characterized by scanning electron microscopy (SEM), transmission electron microscopy (TEM), single crystal $X$-ray diffraction and powder $X$-ray diffraction (XRD), thermal gravimetric analysis (TGA), and Fourier transform infrared spectroscopy (FT-IR). The results showed that two different $\mathrm{Zn}-\mathrm{MOF}$ crystals had been successfully synthesized and that $\left[\mathrm{NaZn}\left(\mathrm{C}_{9} \mathrm{H}_{3} \mathrm{O}_{6}\right)\left(\mathrm{H}_{2} \mathrm{O}\right)_{4}\right] \cdot 1.5 \mathrm{H}_{2} \mathrm{O}$ was prepared by using this method for the first time. The influence of different parameters such as the $\mathrm{pH}$ value, the ratio of reactants, and reaction time on the morphology and size of the Zn-MOFs was studied. Long rod Zn-MOFs with an average size of $\sim 25 \mu \mathrm{m}$ could be obtained in the ionic liquid microemulsions with a molar ratio (organic ligand to metal ion) of $1: 1$ at $\mathrm{pH} 5.98$ for $24 \mathrm{~h}$. The crystal type and morphology of the Zn-MOFs could be controlled by the ionic liquid microemulsions at room temperature. This green synthesis method can be used to study their industrial production.

Received 29th May 2018 Accepted 12 th July 2018 DOI: $10.1039 / \mathrm{c} 8 \mathrm{ra04573a}$ rsc.li/rsc-advances develop facile and green synthetic routes for MOFs by maximizing the efficiency and cleanliness of chemical processes.

Microemulsions are isotropic mixtures of two or more immiscible liquids that coexist in a single phase in the presence of a surfactant or surfactant/co-surfactant mixture. ${ }^{18,19}$ Due to their ability to host a variety of polar (e.g. water) and nonpolar (e.g. aliphatic hydrocarbon) species simultaneously, these thermodynamically stable dispersions provide a unique microenvironment for processing chemical reactions and particularly, a efficient way to synthesize nanomaterials. ${ }^{20-22}$ Besides, each droplet in the microemulsions can be considered as an individual nanoreactor where nanoparticles (NPs) nucleate, grow and crystallize in a confined way. Therefore, nanoparticle size and crystallinity can be better controlled, which is the key to obtain nanomaterials with appropriate and reproducible properties. ${ }^{23}$ However, the main drawback of the microemulsion method to prepare nanomaterials is the use of organic solvents as a component. For the construction of environmentally friendly systems to produce nanomaterials, ionic liquids are regarded as the ideal replacement for traditional organic solvents and form ionic liquid microemulsions because they have not only excellent solvency for both organic and inorganic compounds but also the features of nonflammability, low volatility, high chemical and thermal stability and recyclability. ${ }^{24,25}$ Such ionic liquid based microemulsion systems possess both the advantages of conventional microemulsions and ionic liquids, and have been developed as
College of Science, Huazhong Agricultural University, Wuhan, Hubei 430070, People's Republic of China. E-mail: sqingli@mail.hzau.edu.cn

$\dagger$ Electronic supplementary information (ESI) available: Characterization of the ionic liquid ([Bmim] $\left.\mathrm{PF}_{6}\right)\left({ }^{1} \mathrm{H} \mathrm{NMR}\right)$ and the $\mathrm{Zn}$-MOFs prepared at $\mathrm{RT}$ in the ionic liquid microemulsions from BTC, $\mathrm{Zn}\left(\mathrm{NO}_{3}\right)_{2} \cdot 6 \mathrm{H}_{2} \mathrm{O}$ and $\mathrm{NaOH}$ (FT-IR, TGA and $\mathrm{N}_{2}$ isotherms). CCDC 1055450 . For ESI and crystallographic data in CIF or other electronic format see DOI: 10.1039/c8ra04573a 
promising media for synthesizing some metal nanomaterials, such as gold NPs, ${ }^{26}$ silica NPs, ${ }^{27}$ silver NPs, ${ }^{28}$ palladium NPs, ${ }^{29}$ etc. Recently, differently shaped and sized La-metal-organic frameworks (La-MOFs) have been successfully synthesized in ionic liquid microemulsions, presenting a new route for MOF synthesis. $^{30}$

Here, for the first time, two different Zn-MOF crystals were prepared using $\mathrm{H}_{2} \mathrm{O} / \mathrm{TX}-100 /[\mathrm{Bmim}] \mathrm{PF}_{6}$ microemulsions. This proposed environmentally friendly approach to synthesize $\mathrm{Zn}$ MOFs is simple, requires no energy input, and operates at room temperature. Meanwhile, the influence of the ratio of reactants, the $\mathrm{pH}$ value, and the reaction time on the morphology of the Zn-MOFs was investigated in the ionic liquid microemulsions. The synthesis, size, morphology, crystal structures and thermal properties of the Zn-MOFs have been discussed in detail.

\section{Results and discussion}

The water/TX-100/[Bmim $] \mathrm{PF}_{6}$ system could form microemulsions according to previous work by Gao et al. ${ }^{35}$ The ternary phase diagram is shown in Fig. 1. The three types of subregion including water-in-[Bmim $] \mathrm{PF}_{6}$, bicontinuous, and $\left[\mathrm{Bmim}^{-} \mathrm{PF}_{6}{ }^{-}\right.$ in-water respectively were divided in the single phase region by potentiometric titration. In this work, the organic ligand BTC was selected due to the presence of $-\mathrm{COOH}$ groups, which made the synthesis of MOFs easier at room temperature. Zn-MOFs with different crystal structures and morphologies were synthesized in different subregions of the ionic liquid microemulsions according to well established procedures, and the process is shown in Scheme 1.

According to the ternary phase diagram of the water/TX-100/ $[\mathrm{Bmim}] \mathrm{PF}_{6}$ system, we synthesized the Zn-MOFs using the same ratio of reactants in different regions (A-F) of the microemulsions. The SEM images show that the Zn-MOFs prepared in the microemulsions $\mathrm{A}, \mathrm{B}$ and $\mathrm{C}$, and the microemulsions $\mathrm{D}, \mathrm{E}$ and $\mathrm{F}$ were mainly granular and rod-like, respectively (Fig. 2).

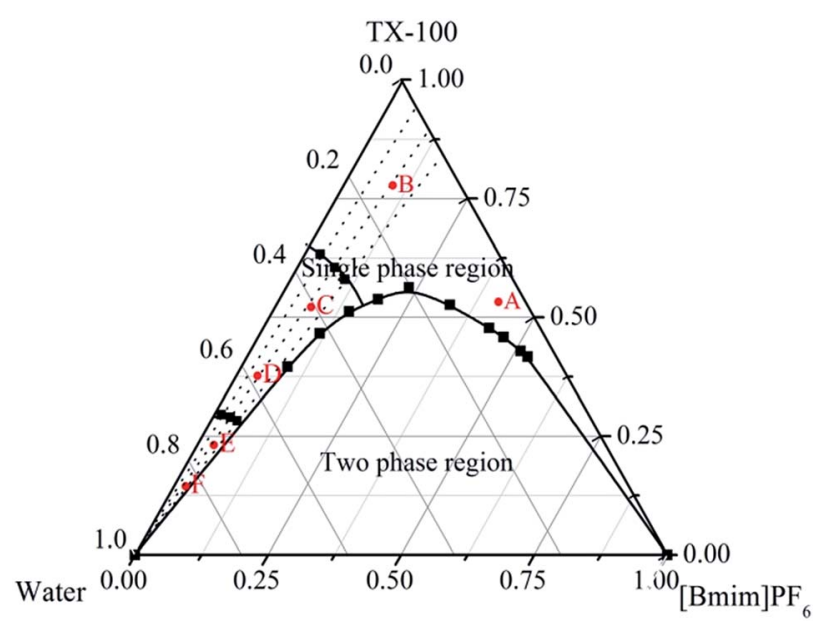

Fig. 1 The phase diagram of the water/TX-100/[Bmim]PF 6 ternary system at $25^{\circ} \mathrm{C}$. A and $\mathrm{B}, \mathrm{C}$ and $\mathrm{D}$, and $\mathrm{E}$ and $\mathrm{F}$, are the water-in-[Bmim] $\mathrm{PF}_{6}$, bicontinuous, and $\left[\mathrm{Bmim} \mathrm{PF}_{6}\right.$-in-water subregions respectively.

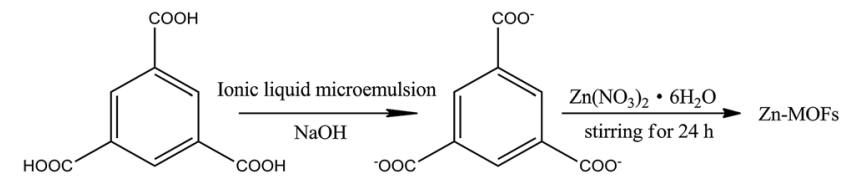

Scheme 1 The preparation of the $\mathrm{Zn}$-MOFs in the ionic liquid microemulsions.

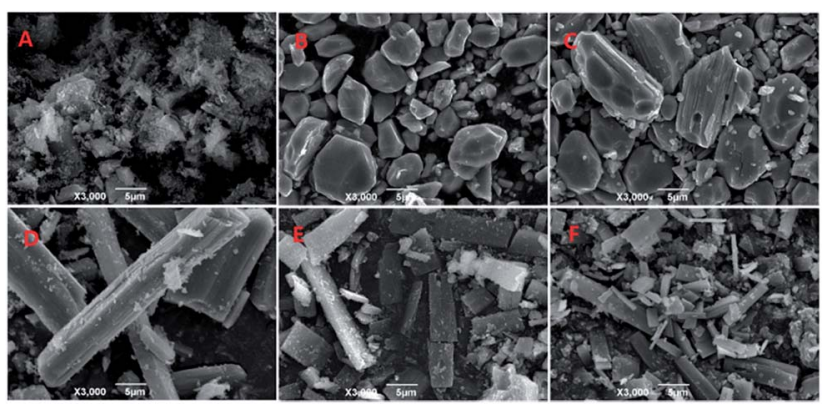

Fig. 2 SEM images of the Zn-MOFs. A-F correspond to the $\mathrm{Zn}-\mathrm{MOFs}$ prepared in the microemulsion $A-F$ regions marked in Fig. 1, respectively.

Therefore, the shape of the Zn-MOFs could be controlled by using different regions of the microemulsions in the synthesis.

Fig. 3 shows the powder XRD patterns of the Zn-MOFs prepared in the corresponding ionic liquid microemulsions marked as A-F respectively in Fig. 1. Samples A, B and F possess different XRD patterns to samples C, D and E. By comparing the powder XRD patterns, it was confirmed that two kinds of completely different crystal structure had been prepared, and the powder XRD patterns matched very well with the simulated patterns of the respective materials (Fig. 4).

The formula of compound $\mathbf{A}$ is $\left[\mathrm{Zn}_{6}(\mathrm{OH})_{3}\left(\mathrm{C}_{9} \mathrm{H}_{3} \mathrm{O}_{6}\right)_{3}\left(\mathrm{H}_{2} \mathrm{O}\right)_{3}\right]$. $7 \mathrm{H}_{2} \mathrm{O}$ (CCDC: 823406). For the first time, we successfully synthesized compound $\mathbf{C}$ using this method. The crystal data and structure parameters of compounds $\mathbf{A}$ and $\mathbf{C}$ are shown in Table 1 . The structure of compound $\mathbf{C}$ was confirmed by single crystal X-ray diffraction analysis. The results suggest that

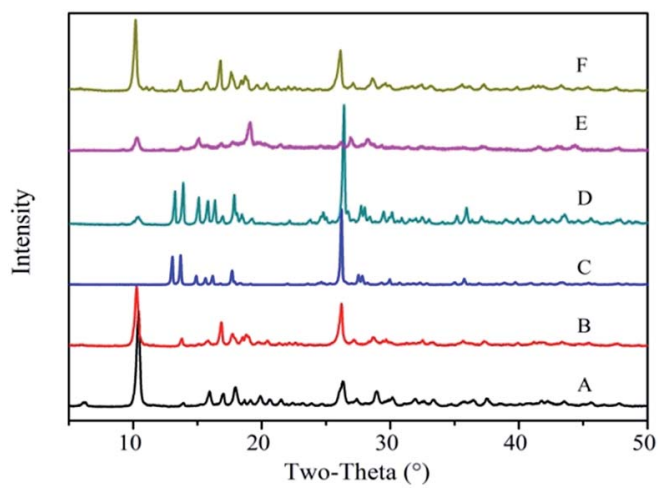

Fig. 3 The powder XRD patterns of the Zn-MOFs prepared in the corresponding ionic liquid microemulsion $\mathrm{A}-\mathrm{F}$ regions marked in Fig. 1. 


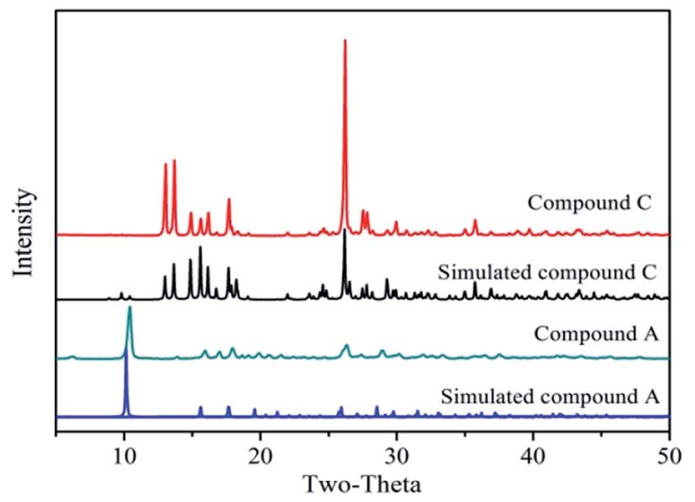

Fig. 4 The powder XRD patterns of compound A (green) and compound $C$ (red) in the ionic liquid microemulsions at room temperature and the simulated patterns for compound $\mathrm{A}$ (blue) and compound C (black)

compound $\mathbf{C}$ is in the triclinic space group $P \overline{1}$, with the formula $\left[\mathrm{NaZn}\left(\mathrm{C}_{9} \mathrm{H}_{3} \mathrm{O}_{6}\right)\left(\mathrm{H}_{2} \mathrm{O}\right)_{4}\right] \cdot 1.5 \mathrm{H}_{2} \mathrm{O}$. There are two $\mathrm{Na}^{+}$ions, one $\mathrm{Zn}^{2+}$ ion, one BTC ligand, eight coordinated $\mathrm{H}_{2} \mathrm{O}$ molecules, and one point five free water molecules scattered at several sites in the asymmetric unit (Fig. 5). Each $\mathrm{Zn}(1)$ connects with two carboxyl oxygen atoms $(\mathrm{O}(1)$ and $\mathrm{O}(4 \mathrm{~A}))$ from two different BTC ligands and three oxygen atoms $(\mathrm{O}(7), \mathrm{O}(8)$, and $\mathrm{O}(9))$ from three coordinated $\mathrm{H}_{2} \mathrm{O}$ molecules, the lengths of the $\mathrm{Zn}-\mathrm{O}$ bonds are in the range 1.978-2.213 $\AA$. Each $\mathrm{Na}$ atom is six-coordinated including $\mathrm{Na}(1)$ and $\mathrm{Na}(2)$ which have different arrangements

Table 1 The crystal data and structure parameters of compounds A and $\mathrm{C}$

\begin{tabular}{|c|c|c|}
\hline & Compound $\mathbf{A}^{13}$ & Compound $\mathbf{C}$ \\
\hline Empirical formula & $\mathrm{Zn}_{6} \mathrm{C}_{27} \mathrm{H}_{32} \mathrm{O}_{31}$ & $\mathrm{NaZnC}_{9} \mathrm{H}_{14} \mathrm{O}_{11.5}$ \\
\hline Formula weight & 1244.75 & 394.56 \\
\hline Temperature (K) & 298 & $296(2)$ \\
\hline Wavelength & 0.71073 & 0.71073 \\
\hline Crystal system & Trigonal & Triclinic \\
\hline Space group & $R 3 c$ & $P \overline{1}$ \\
\hline$a(\AA)$ & $30.159(4)$ & $7.0980(11)$ \\
\hline$b(\AA)$ & $30.159(4)$ & $9.8000(16)$ \\
\hline$c(\AA)$ & $6.9280(14)$ & $11.2043(17)$ \\
\hline$\alpha(\mathrm{deg})$ & 90 & 66.923 \\
\hline$\beta$ (deg) & 90 & 73.598 \\
\hline$\gamma(\mathrm{deg})$ & 120 & 84.720 \\
\hline Volume $\left(\AA^{3}\right)$ & $5457.2(16)$ & $687.68(19)$ \\
\hline$Z$ & 6 & 2 \\
\hline Density $\left(\mathrm{g} \mathrm{cm}^{-3}\right)$ & 2.273 & 1.88 \\
\hline$F\left(\begin{array}{lll}0 & 0 & 0\end{array}\right)$ & 3732 & 402 \\
\hline Crystal size $\left(\mathrm{mm}^{3}\right)$ & $0.15 \times 0.15 \times 0.30$ & $0.05 \times 0.03 \times 0.02$ \\
\hline $\begin{array}{l}\text { Theta range for data } \\
\text { collection (deg) }\end{array}$ & $2.34,33.49$ & $2.30,32.0$ \\
\hline Absorption correction & Multi-scan & Multi-scan \\
\hline Goodness-of-fit on $F^{2}$ & 1.004 & 0.97 \\
\hline $\begin{array}{l}\text { Final } R \text { indices } \\
{[I>2 \operatorname{sigma}(I)]}\end{array}$ & $0.0519,0.1281$ & $0.0510,0.1329$ \\
\hline$R$ indices (all data) & $0.0619,0.1348$ & $0.0977,0.1130$ \\
\hline $\begin{array}{l}\text { Largest diff. peak } \\
\text { and hole }\left(\AA^{-3}\right)\end{array}$ & $2.42,-0.79$ & $0.79,-0.69$ \\
\hline
\end{tabular}

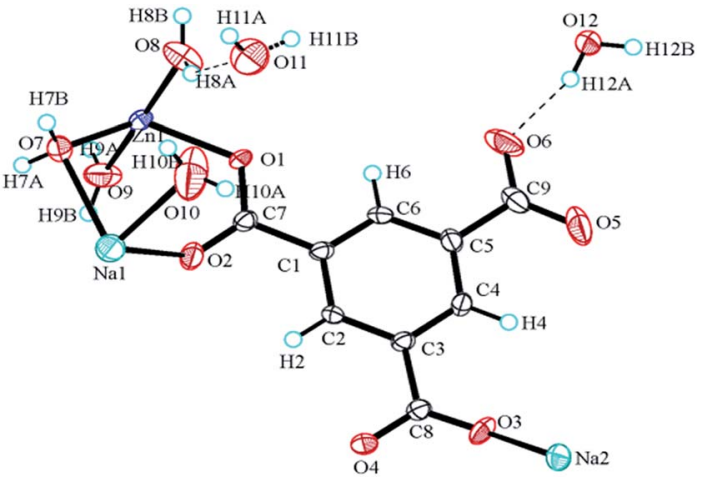

Fig. 5 The coordination environment of compound C.

of ligands. $\mathrm{Na}(1)$ connects two carboxyl oxygen atoms $(\mathrm{O}(2)$ and $\mathrm{O}(2 \mathrm{~A}))$ from two BTC linkers and four oxygen atoms $(\mathrm{O}(7)$, $\mathrm{O}(7 \mathrm{~A}), \mathrm{O}(10)$, and $\mathrm{O}(10 \mathrm{~A})$ ) from four coordinated $\mathrm{H}_{2} \mathrm{O}$ molecules. $\mathrm{Na}(2)$ is bound with four carboxyl oxygen atoms $(\mathrm{O}(1 \mathrm{~A})$, $\mathrm{O}(1 \mathrm{~B}), \mathrm{O}(3)$ and $\mathrm{O}(3 \mathrm{C})$ ) from four BTC linkers and two oxygen atoms $(\mathrm{O}(8 \mathrm{~A})$ and $\mathrm{O}(8 \mathrm{~B}))$ from two coordinated $\mathrm{H}_{2} \mathrm{O}$ molecules. Each BTC in compound $\mathrm{C}$ is completely deprotonated, binding to two separate $\mathrm{Zn}$ atoms and three $\mathrm{Na}$ atoms. Furthermore, the $3 \mathrm{D}$ porous structure of compound $\mathbf{C}$ is shown in Fig. 6.

The FT-IR spectra of the Zn-MOFs are shown in Fig. $S 1$ in the ESI. $\dagger$ The broad absorption bands from the asymmetric and symmetric stretching vibrations of water molecules appear at $3700-2800 \mathrm{~cm}^{-1}$. The Zn-MOFs have strong absorption bands at 1629 and $1544 \mathrm{~cm}^{-1}$, which can be attributed to the stretching vibrations and asymmetric stretching vibrations of the carboxylate groups (COOM) in the BTC ligand, respectively. The vibrations of the $\mathrm{C}-\mathrm{H}$ groups in the benzene ring give adsorption bands from $763-731 \mathrm{~cm}^{-1}$. The characteristic peaks of protonated carboxyl groups (1730-1680 $\left.\mathrm{cm}^{-1}\right)$ are not observed in the FT-IR spectra, indicating that the BTC has been completely deprotonated in the reaction and acts as the bridging ligand to form Zn-MOFs.

The thermal stabilities of compounds $\mathbf{A}$ and $\mathbf{C}$ were measured by TGA (Fig. S2 in the ESI $\dagger$ ) in an air atmosphere, and the related data indicated that thermal decomposition of compounds $\mathbf{A}$ and $\mathbf{C}$ proceeded with two distinct weight losses between 30 and $650{ }^{\circ} \mathrm{C}$. The first weight loss was attributed to the departure of all the water molecules in the temperature range $80-150{ }^{\circ} \mathrm{C}$, without further weight loss up to $400{ }^{\circ} \mathrm{C}$. The second weight loss corresponded to the release of the organic

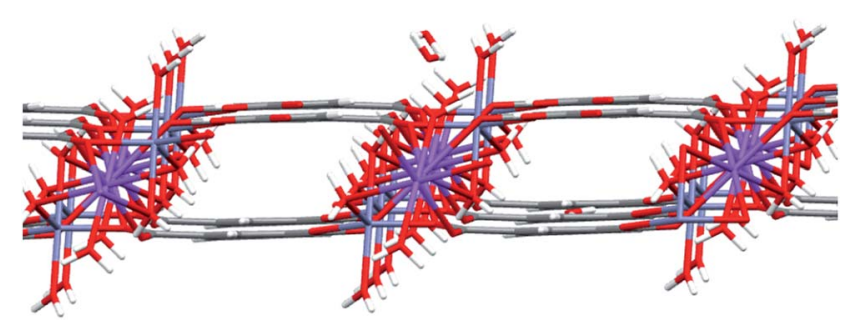

Fig. 6 The 3D network structure of compound C. 
ligands and happened from 400 to $550{ }^{\circ} \mathrm{C}$, resulting in $\mathrm{ZnO}$ and $\mathrm{Na}_{2} \mathrm{CO}_{3}$ as the residue. The results showed that the $\mathrm{Zn}-\mathrm{MOF}$ had been prepared.

The specific surface areas of the $\mathrm{Zn}$-MOFs were characterized by the $\mathrm{N}_{2}$ adsorption-desorption method, and an adsorptiondesorption isotherm curve is presented in Fig. S3 in the ESI. $\dagger$ The BET surface area of the Zn-MOFs synthesized in the ionic liquid microemulsion $\mathrm{C}$ region was calculated to be $6.137 \mathrm{~m}^{2} \mathrm{~g}^{-1}$. Such a low surface area of the Zn-MOFs may be due to the fact that a considerable number of the open pores were blocked by the ionic liquid microemulsion during the synthesis processes.

As an example, the Zn-MOFs prepared in the microemulsion F region marked in Fig. 1 were chosen to study the effect of $\mathrm{pH}$ values on the morphology of the Zn-MOFs. As shown in Fig. 7, when the $\mathrm{pH}$ was 5.98 , the morphology of the Zn-MOFs was a long rod. The higher the $\mathrm{pH}$ value, the more particles with small sizes were produced on the surface of the Zn-MOFs. This could be attributed to the etching effect on the surface of the $\mathrm{Zn}$ MOFs under the strongly alkaline conditions.

In order to evaluate whether the ratio of reactants had an effect on the morphology of the Zn-MOFs, different ratios of reactants were selected to study the morphology of the product in the microemulsion $\mathrm{F}$ region marked in Fig. 1. The SEM images of the Zn-MOFs show that different morphologies of the Zn-MOFs have been prepared with different ratios of reactants (Fig. 8). When the mole ratio of organic ligand (BTC) to metal ion $\left(\mathrm{Zn}^{2+}\right)$ was 0.5 , the morphology of the $\mathrm{Zn}$-MOFs prepared was a rod. As the mole ratio increased to 2.0, the morphology of the product was a quadrangle, which could be due to the influence of excess organic ligand. $\mathrm{Zn}^{2+}$ was linked with the excess of the organic ligand to form the quadrangular structure. It can be shown from the result in Fig. 8 that the morphology of the $\mathrm{Zn}$-MOFs depends strongly on the ratio of reactants.

In order to demonstrate the effect of reaction time on the size and morphology of the Zn-MOFs, different reaction times were studied. Fig. 9 shows that the size of the Zn-MOFs was the largest at $24 \mathrm{~h}$ and then the length of the $\mathrm{Zn}-\mathrm{MOF}$ changed from long to short with the extension of reaction time, which could be due to the effect of excessive stirring causing the long

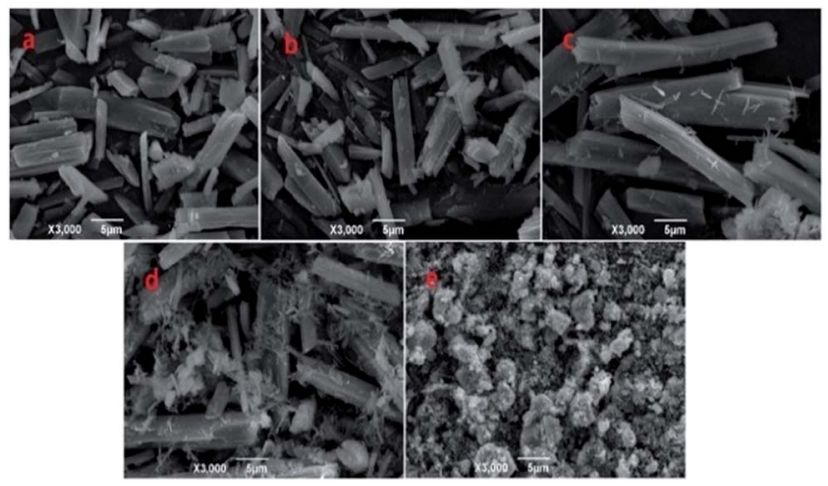

Fig. 7 SEM micrographs of the Zn-MOFs which were prepared in the ionic liquid microemulsion $\mathrm{F}$ region marked in Fig. 1. (a) $\mathrm{pH}=5.98$, (b) $\mathrm{pH}=8.51$, (c) $\mathrm{pH}=9.89$, (d) $\mathrm{pH}=12.0$, and (e) $\mathrm{pH}=13.5$.

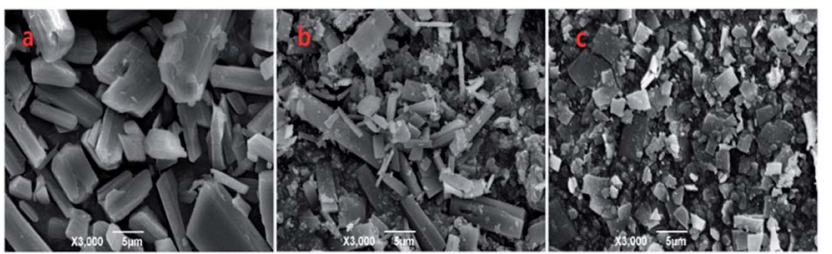

Fig. 8 SEM micrographs of $\mathrm{Zn}$-MOFs which were prepared in the ionic liquid microemulsion F region marked in Fig. 1. (a) $n$ (BTC) $: n\left(Z^{2+}\right)=$ $1: 2$, (b) $n(\mathrm{BTC}): n\left(\mathrm{Zn}^{2+}\right)=1: 1$, and (c) $n$ (BTC) $: n\left(\mathrm{Zn}^{2+}\right)=2: 1$.

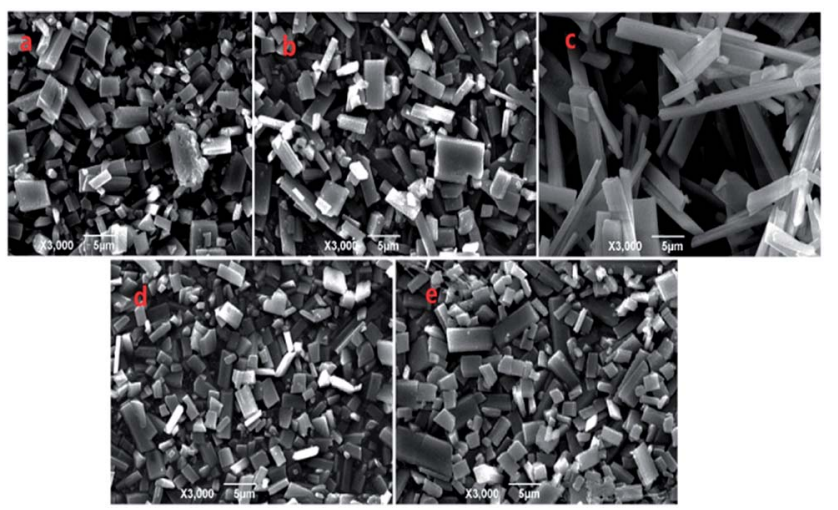

Fig. 9 SEM micrographs of $\mathrm{Zn}$-MOFs which were prepared in the ionic liquid microemulsion $\mathrm{F}$ region marked in Fig. 1. (a) $T=6 \mathrm{~h}$, (b) $T=12 \mathrm{~h}$, (c) $T=24 \mathrm{~h},(\mathrm{~d}) \mathrm{T}=36 \mathrm{~h}$, and (e) $T=48 \mathrm{~h}$.

rod structures to break off after $24 \mathrm{~h}$. When the reaction time was up to $24 \mathrm{~h}$, the morphology of the Zn-MOFs prepared in the ionic liquid microemulsions was a long rod with an average size of $\sim 25 \mu \mathrm{m}$ (Fig. 9c).

According to the previous literature, the shape of the MOFs depends on the shape of the droplets in the corresponding microemulsions, but the size of the final MOFs was much larger than that of the droplets in the microemulsions. Besides, the dispersed droplets in the $[\mathrm{Bmim}] \mathrm{PF}_{6}$-in-water microemulsion are cylindrical, which produce rod-like final MOFs. ${ }^{30}$ Therefore, the rod-like $\mathrm{Zn}$-MOFs prepared in the microemulsion $\mathrm{F}$ region ([Bmim] $\mathrm{PF}_{6}$-in-water) have a good agreement with the previous study. The mechanism for controlling the morphology could be summarized as follows: the $\mathrm{Zn}^{2+}$ dissolves in the water and the organic ligands (BTC) dissolve in the ionic liquid. Zn-MOF nuclei are formed by the coordination reaction of the $\mathrm{Zn}^{2+}$ ions and the protonated BTC ligands at the water/IL (ionic liquid) interface in the droplets of the corresponding microemulsions, and grow gradually. The shape of the droplets in the corresponding microemulsions mainly determines the shape of the final Zn-MOFs.

\section{Conclusions}

The study of the controlled morphologies of the Zn-MOFs prepared in ionic liquid microemulsions is very interesting. In this work, we have successfully synthesized metal-organic frameworks which combine a transition metal $\left(\mathrm{Zn}^{2+}\right)$ and 
aromatic BTC ligands in ionic liquid microemulsions at room temperature and two different Zn-MOF crystal structures have also been afforded. The influence of different parameters such as the $\mathrm{pH}$ value, the ratio of reactants and the reaction time on the morphology and size of the Zn-MOFs was demonstrated. Although, to some extent, the low surface area of the Zn-MOFs synthesized in these ionic liquid microemulsions may restrict their application range, the synthesis of metal-organic frameworks in ionic liquid microemulsions at room temperature is simple and fits the green chemistry idea, and we believe that this method can also be widely applied in synthesizing new materials with various sizes and morphologies.

\section{Experimental}

\section{Materials}

1,3,5-Benzenetricarboxylic acid (BTC) with a purity of $>97 \%$ was purchased from Accela ChemBio Co., Ltd. Nonionic surfactant Triton X-100 (TX-100, polyoxyethylene (10) isooctylphenyl ether, M.W. = 646, Sinopharm Chemical Reagent Co., Ltd.,) was used without further purification. $\mathrm{Zn}\left(\mathrm{NO}_{3}\right)_{2} \cdot 6 \mathrm{H}_{2} \mathrm{O}$ and $\mathrm{NaOH}$ were purchased from Sinopharm Chemical Reagent Co., Ltd. Water was purified with a Milli-Q $18.3 \mathrm{M} \Omega \mathrm{cm}^{-1}$ water system. All solvents and reagents for the syntheses were used as received from commercial sources without further purification.

\section{Synthesis of the ionic liquid $[\mathrm{Bmim}] \mathrm{PF}_{6}$}

Synthesis of the ionic liquid was performed in a $250 \mathrm{~mL}$ round bottom flask using a procedure similar to that previously described..$^{31-34}$ The ionic liquid 1-butyl-3-methylimidazolinium chloride $(30.14 \mathrm{~g}, 0.172 \mathrm{~mol})$ was added to react with $20 \%$ (theoretical) excess of $\mathrm{KPF}_{6}(37.98 \mathrm{~g}, 0.206 \mathrm{~mol})$ in water (150 $\mathrm{mL}$ ) under continuous stirring at room temperature for $12 \mathrm{~h}$. The organic layer in the reaction mixture was washed with water $(3 \times 30 \mathrm{~mL})$ after 12 hours and the product was dried under vacuum for 8 hours, the pure ionic liquid ([Bmim] $\mathrm{PF}_{6}$ ) was obtained and the yield was $32.45 \mathrm{~g}(0.114 \mathrm{~mol}, 66.35 \%) .{ }^{1} \mathrm{H}$ NMR characterization is presented in Fig. S4 in the ESI. $\dagger^{1} \mathrm{H}$ NMR (600 MHz, $\delta$, ppm, DMSO): 2.442 (s), 9.048 (s, H), 7.711$7.714(\mathrm{~d}, \mathrm{H}), 7.645-7.647$ (d, H), 3.801 (s, 3H), 4.102-4.126 (t, $2 \mathrm{H}), 1.696-1.745(\mathrm{~m}, 2 \mathrm{H}), 1.186-1.223(\mathrm{q}, 2 \mathrm{H}), 0.848-0.872$ $(\mathrm{t}, 3 \mathrm{H})$.

\section{Preparation of the Zn-MOFs}

For the experiments, the ionic liquid microemulsions with desired compositions containing water, $[\mathrm{Bmim}] \mathrm{PF}_{6}$, and Triton $\mathrm{X}$-100 were prepared using a previously reported method. ${ }^{35}$ $\mathrm{Zn}\left(\mathrm{NO}_{3}\right)_{2} \cdot 6 \mathrm{H}_{2} \mathrm{O}(1.0 \mathrm{mmol}), \mathrm{NaOH}(1.0 \mathrm{mmol})$ and BTC (1.0 $\mathrm{mmol})$ were added into the ionic liquid microemulsions $(20 \mathrm{~g})$. The mixed solution was stirred for 24 hours at room temperature. Then, the product was collected by centrifugation at $4500 \mathrm{rpm}$ and washed with ethanol three times $(3 \times 20 \mathrm{~mL})$ to remove the surfactant and $[\mathrm{Bmim}] \mathrm{PF}_{6}$. Then, the white products were dried in a vacuum oven at $60{ }^{\circ} \mathrm{C}$ for 24 hours.

\section{Material characterization}

Powder X-ray diffraction data from the studied samples were collected on a D8 ADVANCE with $\mathrm{Cu} \mathrm{K} \alpha$ radiation $(\lambda=1.5418 \AA)$. FT-IR spectra were obtained on a Bruker VERTEX70 FT-IR spectrometer using $\mathrm{KBr}$ pellets prepared with sample powders, and measured in the wavenumber range 4000$400 \mathrm{~cm}^{-1}$. Morphology analyses for Zn-MOFs were carried out on a NTC JSM-6390LV. Thermogravimetric (TG) analyses was performed in an air atmosphere with a heating rate of $10{ }^{\circ} \mathrm{C} \mathrm{min}^{-1}$ from 25 to $600{ }^{\circ} \mathrm{C}$, using a NETZSCH TG209C instrument. The single crystal data were collected using a Bruker SMART X-ray diffractometer, equipped with an APEXCCD area detector.

\section{Conflicts of interest}

There are no conflicts to declare.

\section{Acknowledgements}

This research was financially supported by the Natural Science Foundation of Hubei Province of China (2018CFB166) and the Fundamental Research Funds for the Central Universities (2662017QD029, 2662018JC009).

\section{Notes and references}

1 N. L. Rosi, J. Kim, M. Eddaoudi, B. Chen, M. O'Keeffe and O. M. Yaghi, J. Am. Chem. Soc., 2005, 127, 1504.

2 H. C. Zhou, J. R. Long and O. M. Yaghi, Chem. Rev., 2012, 112, 673.

3 J. R. Li, J. Sculley and H. C. Zhou, Chem. Rev., 2012, 112, 869. 4 S. Q. Ma and H. C. Zhou, Chem. Commun., 2010, 46, 44.

5 X. Huang, Y. Chen, Z. Lin, X. Ren, Y. Song, Z. Xu, X. Dong, X. Li, C. Hu and B. Wang, Chem. Commun., 2014, 50, 2624.

6 T. Zhang and W. Lin, Chem. Soc. Rev., 2014, 43, 5982.

7 E. Haque, J. E. Lee, I. T. Jang, Y. K. Hwang, J. S. Chang, J. Jegal and S. H. Jhung, J. Hazard. Mater., 2010, 181, 535.

8 S. Lin, Z. Song, G. Che, A. Ren, P. Li, C. Liu and J. Zhang, Microporous Mesoporous Mater., 2014, 193, 27.

9 Z. Q. Li, A. Wang, C. Y. Guo, W. N. Hu and Y. F. Tai, Chem. J. Chin. Univ., 2013, 34, 2470.

10 P. Horcajada, R. Gref, T. Baati, P. K. Allan, G. Maurin, P. Couvreur, G. Ferey, R. E. Morris and C. Serre, Chem. Rev., 2012, 112, 1232.

11 L. Xie, S. Liu, Z. Han, R. Jiang, H. Liu, F. Zhu, F. Zeng, C. Su and G. Ouyang, Anal. Chim. Acta, 2015, 853, 303.

12 L. E. Kreno, K. Leong, O. K. Farha, M. Allendorf, R. P. Van Duyne and J. T. Hupp, Chem. Rev., 2012, 112, 1105.

13 Y. Fu, G. Li, F. Liao, M. Xiong and J. Lin, J. Mol. Struct., 2011, 1004, 252.

14 I. A. Ibarra, P. A. Bayliss, E. Perez, S. Yang, A. J. Blake, H. Nowell, D. R. Allan, M. Poliakoff and M. Schroder, Green Chem., 2012, 14, 117.

15 F. Alosfur, M. Jumali, S. Radiman, N. Ridha, M. Yarmo and A. Umar, Nanoscale Res. Lett., 2013, 8, 1. 
16 Z. Q. Li, L. G. Qiu, T. Xu, Y. Wu, W. Wang, Z. Y. Wu and X. Jiang, Mater. Lett., 2009, 63, 78.

17 D. Denysenko, M. Grzywa, M. Tonigold, B. Streppel, I. Krkljus, M. Hirscher, E. Mugnaioli, U. Kolb, J. Hanss and D. Volkmer, Chem.-Eur. J., 2011, 17, 1837.

18 I. Danielsson and B. Lindman, The definition of microemulsion, Colloids Surf., A, 1981, 3, 391.

19 L. E. Scriven, Equilibrium bicontinuous structure, Nature, 1976, 263, 123.

20 M. P. Pileni, Nat. Mater., 2003, 2, 145.

21 R. Zhang, J. Liu, J. He, B. Han, T. Jiang, D. Shen, J. Huang and H. Gao, Chem.-Eur. J., 2003, 9, 2167.

22 R. P. Bagwe, C. Yang, L. R. Hilliard and W. Tan, Langmuir, 2004, 20, 8336.

23 L. Zhang, Y. Wang, L. Tong and Y. Xia, Nano Lett., 2014, 14, 4189.

24 X. Kang, X. Sun, X. Ma, P. Zhang, Z. Zhang, Q. Meng and B. Han, Angew. Chem., Int. Ed., 2017, 56, 12683.

25 X. Kang, X. Sun and B. Han, Adv. Mater., 2016, 28, 1011.

26 C. Fu, H. Zhou, D. Xie, L. Sun, Y. Yin, J. Chen and Y. Kuang, Colloid Polym. Sci., 2010, 288, 1097.
27 M. Zhao, L. Zheng, X. Bai, N. Li and L. Yu, Colloids Surf., A, 2009, 346, 229.

28 M. Harada, Y. Kimura, K. Saijo, T. Ogawa and S. Isoda, J. Colloid Interface Sci., 2009, 339, 373.

29 G. Zhang, H. Zhou, J. Hu, M. Liu and Y. Kuang, Green Chem., 2009, 11, 1428.

30 W. T. Shang, X. C. Kang, H. Ning, J. L. Zhang, X. G. Zhang, Z. H. Wu, G. Mo, X. Q. Xing and B. X. Han, Langmuir, 2013, 29, 13168.

31 I. A. Shkrob, T. W. Marin, H. M. Luo and S. Dai, J. Phys. Chem. $B, 2013,117,14372$.

32 G. A. G. Porras, J. Zeitouny, A. Gomila, B. Douziech, N. Cosquer, F. Conan, O. Reinaud, P. Hapiot, Y. L. Mest, C. Lagrost and N. L. Poul, Dalton Trans., 2014, 43, 6436.

33 J. P. Chen and X. S. Zhu, Spectrochim. Acta, Part A, 2015, 137, 456.

34 T. Endo, H. Masu, K. Fujii, T. Morita, H. Seki, S. Sen and K. Nishikawa, Cryst. Growth Des., 2013, 13, 5383.

35 Y. N. Gao, B. S. Han, B. X. Han, G. Z. Li, D. Shen, Z. H. Li, J. M. Du, W. G. Hou and G. Y. Zhang, Langmuir, 2005, 21, 5681. 